\title{
Design And Application Of Four Phase Separation And Back Flushing High Pressure Well Flushing Vehicle
}

\author{
Zhen Zhang ${ }^{1}$, Zhou Dai ${ }^{1}$, Chao $\mathrm{Ma}^{1}$, Shuping $\mathrm{Li}^{2}$, Rui Zhou ${ }^{3}$ \\ ${ }^{1}$ Hebei Bohai Petroleum Equipment Special Vehicle Co.,Ltd. Renqiu 062550, China \\ ${ }^{2}$ North China Petroleum Steel Pipe Anticorrosion Branch of CNPC Bohai Petroleum Equipment Manufacturing Co., Ltd. \\ Qingxian 062650, China \\ ${ }^{3}$ NanJing Julong Steel Pipe Co.,Ltd.
}

Nanjing 210061, China

Keywords: four phase separation, back flushing, high pressure well flushing vehicle, well flushing fluid

\begin{abstract}
In order to solve the problems such as poor purification, complex circulation of well flushing and longtime of well flushing for well flushing fluid, in this paper, we design a four phase separation and back flushing high pressure well flushing vehicle and apply it to the actual situation. In this design, the floatation sedimentation oil-water separation technology, fiber ball rapid filtration technology, cyclone sand removal technology and the magnetic filtration technology are used to purify the return well flushing fluid as well flushing. These four phase matters include sediment, sump oil, rust and water, that are in the well flushing liquid and separated directly. Then the purified well washing liquid is injected into the well in closed circulation washing. The design is applied in the actual cleaning and purification of the well flushing fluid, and proved that the design is advanced and practical as the results are compared.
\end{abstract}

\section{Introduction}

At present, the main application of the water injection well flushing vehicle mostly uses combined structure that includes the oblique plate oil remover, walnut shell, and fiber ball filter. This kind of structure has many disadvantages, such as poor purification, complex circulation of well flushing and longtime of well flushing.
Firstly, because the inclined plate oil remover is used to remove the oil from the self-agglomeration capacity of oil beads, so that the oil bubble floating speed is slow, then oil-water separation is slow and separation is not complete. Secondly, excessive oil and suspended solids are filtered through walnut shell of vehicle and fiber ball filter, that easily to be polluted and harden, so they loss regenerative capacity and cause mechanical failure. In addition, it is necessary to go back to the sewage treatment station regularly for back flushing and sewage treatment, which shortens the service life of walnut shell and fiber ball filter, so the cost of well flushing increases.

The conventional well flushing vehicle must be unloaded to carry out the well flushing operation, that has these problems such as that the pressure discharge time is long, destroy the water injection state, and so on. There are some types of well flushing vehicle are developed, improvement, and application in [1-5], such as JHX5280TJC, DQG5200TJC, JHX5252TJC, JHX5280TJC, JHX5280TSC and so on. The 4-Phase separation for drilling fluid recovered from ground during drilling process was studied, and the focuses were emphasized on the separation system of drilling fluid with high density and high viscosity that could cause gas cut at high- pressure, ultra-high- pressure gas layer and well control, in [6,7].

\section{The design of floatation sedimentation oil-water separation technology}

The design of floatation sedimentation oil-water separation 
technology is the well flushing fluid treatment system that combines floatation sedimentation tank and rapid filter. The floatation sedimentation tank is the core device of the machine in addition to oil and its internal structure includes inclined plate and air dissolving pump. If the dissolved air water is pass into the floatation sedimentation tank, which made the non water soluble micro oil beads attached to the micro bubbles and then float rapidly, the most of emulsified oil and dispersed oil are converted into floating oil in liquid. The floating oil and suspended matter will be scraped to the oil collecting trough with the scraper. The scum will be transported to the oil tank with oil collecting pipe. The clear water will be sent to clear water area with the water collecting pipe and then injected into the well with the three-cylinder pump. There are emptying pipes in each area of floatation sedimentation tank, those ensure that the liquid in the tank can be discharged.

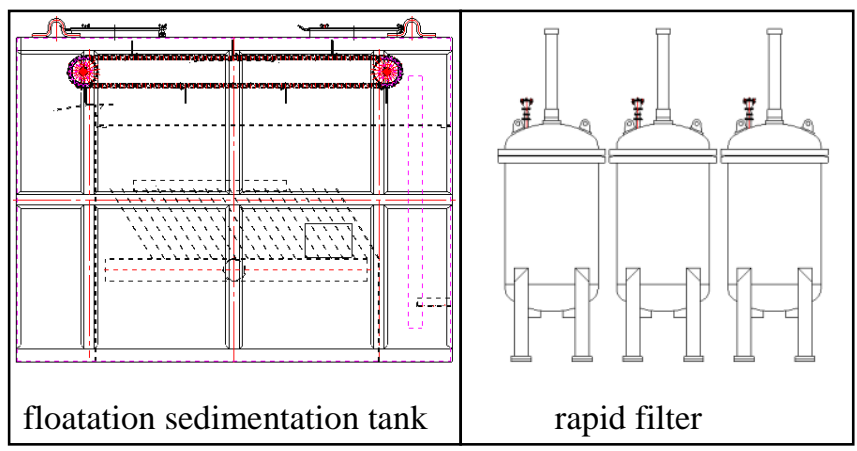

Figure 1. The structure of treatment system for the well flushing fluid.

The filter system is made up of fast filter that contains three fiber balls, so the same volume of filter unit has a larger filter area. The fiber material is used as the filter material, so the suspended matter will not be stuck on the filter material and then it is easy to be removed as back flushing. The pressure mechanism is used to control the compression and porosity of the fiber filter material, so as to achieve high filter precision and good back flushing effect. Because that the fiber filter material is compacted with machine, so there is no the problem that the filter precision reduces as preliminary stage after back flushing. The distribution of effluent and back flushing water is controlled by the pneumatic control valve and pressure difference and then it can be self-back flushing online, so that the back flushing pool and pump are not needed. The effect of removing oil and suspended matter is obvious, and the oil removal rate can reach more than $95 \%$, thus reducing the working load of the subsequent filter. The structure of treatment system for the well flushing fluid is shown in figure 1. The flow chart of the well flushing fluid is shown in figure 2.

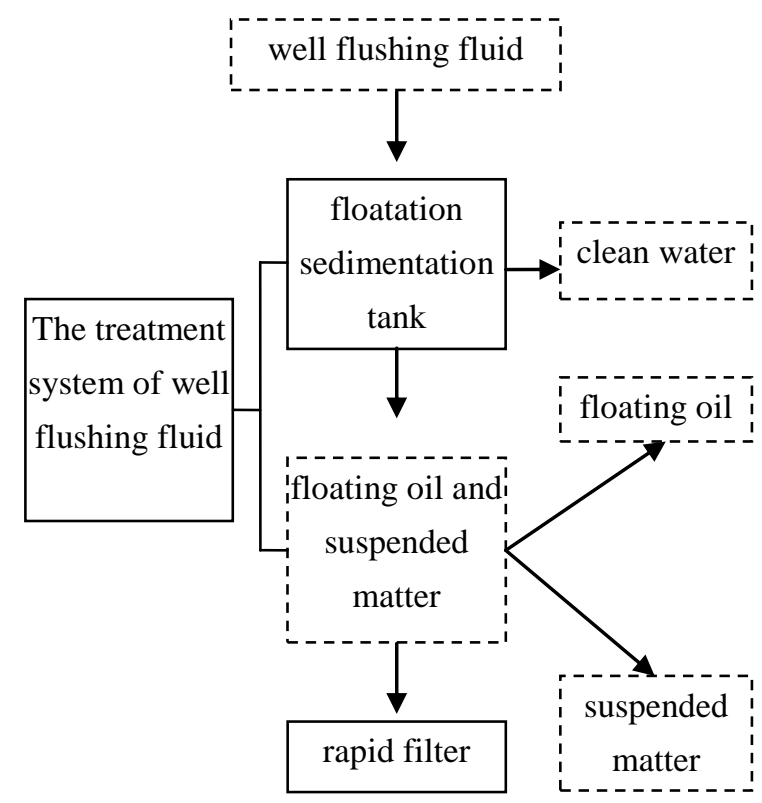

Figure 2. The flow chart of the well flushing fluid

\section{The design of fiber ball rapid filtration technology}

The fiber ball filter which is made up of fiber filament is different from the traditional rigid material and it is an elastic filter material, so the void volume is larger. Because that the fiber filter material is compacted with machine, so there is no the problem that the filter precision reduces as preliminary stage after back flushing. In the filtration process, the filter layer porosity decreases gradually from the top to the bottom in accordance with the flow direction of water. That meets the large and small space distribution of the ideal filter material. Compared with the traditional filter, the design of the fiber ball filter material has these advantages, such as high filter speed $\left(20 \sim 60 \mathrm{~m}^{3} / \mathrm{h}\right)$, large amount of stopping mud, long working period and so on. The pressure on a fiber ball releases as back flushing and the fiber ball is loosed and expanded under the action of the cylinder contraction, which can achieve the purpose of cleaning. The fiber ball filter has these characteristics such as high filter speed, large interception capacity, thorough 
back flushing, compact equipment, small floor area, martindate abrasion, resistant to corrosion and so on. The equipment structure of fiber ball rapid filtration technology is shown in figure 3 and its performance parameters are shown in table I.

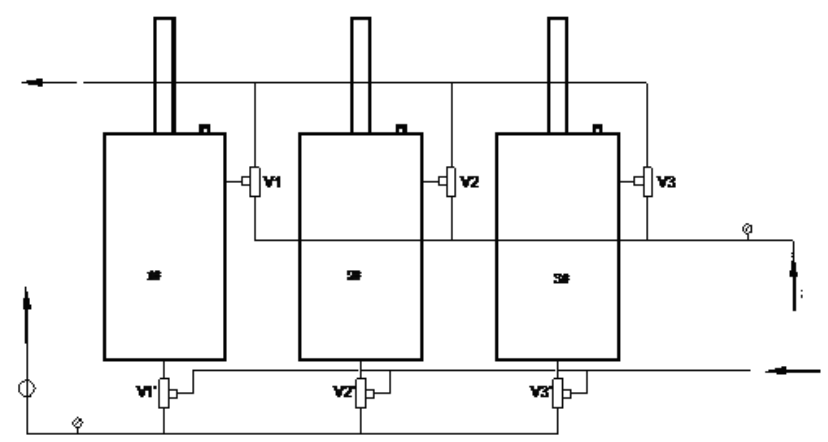

Figure 3. The equipment structure of fiber ball rapid filtration technology

Table I . These performance parameters of fiber ball rapid filtration technology.

\begin{tabular}{|c|c|}
\hline Single processing capacity & $4 \sim 180 \mathrm{~m}^{3} / \mathrm{h}$ \\
\hline Water back flushing strength & $10 \mathrm{~L} / \mathrm{min} \cdot \mathrm{m}$ \\
\hline $5 \mu \mathrm{m}$ Particle removal rate & $\geq 96 \%$ \\
\hline Filtration rate & $20 \sim 60 \mathrm{~m}^{3} / \mathrm{h}$ \\
\hline Suspended matter removal rate & $86-96 \%$ \\
\hline Backflushing time & $4 \sim 6 \mathrm{~min}^{\circ}$ \\
\hline Backflushing water ratio & $1 \sim 3 \%$ \\
\hline $10 \mu \mathrm{m}$ Parti-cle removal & $\geq 95 \%$ \\
\hline rate & \\
\hline r
\end{tabular}

\section{The design of cyclone sand removal technology and the magnetic filtration technology}

The cyclone desander is mainly composed of vortex shell, cone, nozzle, liquid inlet and liquid outlet. The liquid enters into the vortex shell from the liquid inlet, and the liquid forms a vortex along the inner wall of the vortex shell under the action of the input liquid pressure. The centrifugal acceleration is different because of the different density of the medium in the liquid, so the centrifugal force is different. Therefore, these mediums of different density are separated. Under the action of centrifugal force, the higher density medium moves toward the wall of the vortex shell. And it slides to enter the cone downward deposition along the wall of the vortex shell under the action of the gravity of its own. Under the action of liquid pressure, the smaller density medium is discharged upward from the discharge port. So that these different density mediums are separated by cyclone desander

According to the maximum set flow rate of the equipment, three cyclones are combined and then remove the sand. The large flow cyclone is arranged at the first stage, and is used for removing the mud sand of the larger particles in the liquid. The liquid that discharged from the first discharge port enters the second stage cyclone. In the second stage, the two parallel cyclones are used to remove the residual mud sand. The cyclone parameters are shown in table II

Table II . The cyclone parameters

\begin{tabular}{|c|c|c|}
\hline & First stage & Second stage \\
\hline Treatment capacity & $30 \mathrm{~m}^{3} / \mathrm{h}$ & $15 \mathrm{~m}^{3} / \mathrm{h}$ \\
\hline Working pressure & $1.0 \mathrm{MPa}$ & $0.8 \mathrm{MPa}$ \\
\hline $\begin{array}{c}\text { working } \\
\text { temperature }\end{array}$ & $\leq 120^{\circ} \mathrm{C}$ & $30 \sim 74 \mu \mathrm{m}$ \\
\hline $\begin{array}{c}\text { Treatment } \\
\text { granularity }\end{array}$ & $40 \sim 100 \mu \mathrm{m}$ & $99.8 \%$ \\
\hline
\end{tabular}

The magnetic filtration technology is the permanent magnet is installed in the magnetic separator. Its function is that magnetize particles and ions in wastewater and then they form large particles precipitate, so that rust and some impurities can be removed.

\section{Application}

In this paper, according to the technical scheme of four phase separation and back flushing, a high pressure well flushing vehicle is designed. Its practical application is in the oil well in figure 4 and verified the effectiveness of the proposed design.

According to the actual well flushing process, the collected separation samples are shown in figure 5 using the technical 
scheme. The content of oil and impurity in water are compared before and after flushing well and shown in table III.

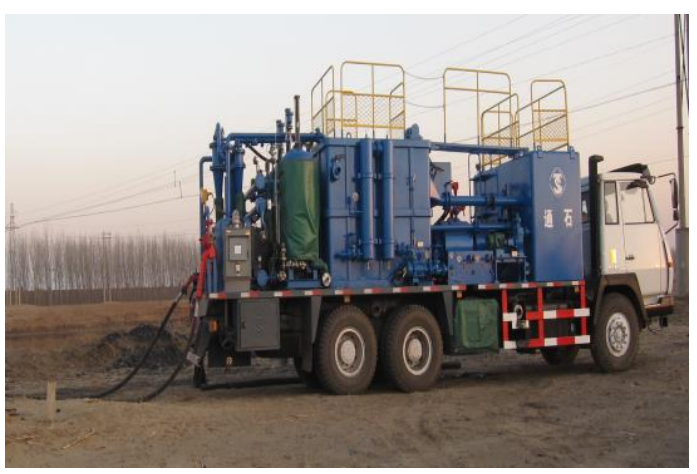

Figure 4. the well flushing scene of four phase separation back flushing high pressure flushing vehicle

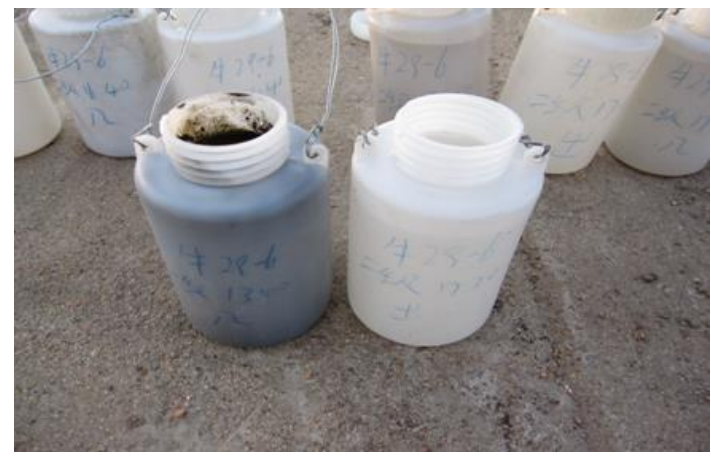

Figure 5. The separation medium

Table III. Comparison of water quality parameters before and after well flushing

\begin{tabular}{|c|c|c|c|c|}
\hline \multirow{2}{*}{ Well No. } & \multicolumn{2}{|c|}{ Before } & \multicolumn{2}{c|}{ After } \\
\cline { 2 - 5 } & Oil & Impurity & Oil & Impurity \\
$(\mathrm{mg} / \mathrm{L})$ & $(\mathrm{mg} / \mathrm{L})$ & $(\mathrm{mg} / \mathrm{L})$ & $(\mathrm{mg} / \mathrm{L})$ \\
\hline $1 \#$ & 5.8 & 182 & 2 & 72 \\
\hline $2 \#$ & 6.1 & 150 & 0 & 60 \\
\hline $3 \#$ & 86 & 118 & 24 & 58 \\
\hline $4 \#$ & 3.2 & 68 & 1.4 & 42 \\
\hline
\end{tabular}

\section{Conclusion}

In this paper, the high pressure well flushing vehicle is based on well flushing fluid treatment technology of the oil field water injection, and design an environmental protection water treatment equipment of cycle cleaning injection. It is mainly used for treating the well flushing fluid when the oil field is purified. The effective removal of sediment, floating oil, suspended matter, rust and other pollutants. The flushing liquid is purified and reinjected into the well in the closed circulation. The practical application proves that the design is reasonable and effective, and it needs to be further applied and improved in other conditions.

\section{References}

[1] Kejian Chen, Zhaomin Wu, Wenquan Li, et al. "Development of JHX5280TJC type high pressure well flushing vehicle", China Petroleum Machinery, vol.37(8), pp.67-69.

[2] Yanwei Zhang, Yanchun Song, Zhongwei Liu. "Development of DQG5200TJC type self circulation well flushing vehicle for water injection well", China Petroleum Machinery, vol.39(10), pp.100-102, (2011).

[3] Bingxin Huo. "Improvement and application of well flushing vehicle for JHX5252TJC type", China Petroleum Machinery, vol.37(7), pp.63-65, (2009).

[4] Gang $\mathrm{Xu}$, Xiaoyun Chen, Minghua Liu, et al. "Application and improvement of model JHX5280TJC well-flushing truck", China Petroleum Machinery, vol.41(2), pp.102-104, (2013).

[5] Pingan Shen, Yuanqing Wang, Zhaomin Wu, et al. "Development of sand flushing car for JHX5280TSC type", China Petroleum Machinery, vol.36(10), pp.51-53, (2008).

[6] Jin Feng, Gang Liu, Manlai Zhang, et al. "Study on 4phase separation of drilling fluid with high density and high viscosity", Journal of Filtration \& Separation, Vol.16(1), pp.24-28, (2006).

[7] Yi Yang. "Process principles and structure analysis of four-phase separators used for drilling", Oil Field Equipment, Vol.42(12), pp.74-77, (2013). 